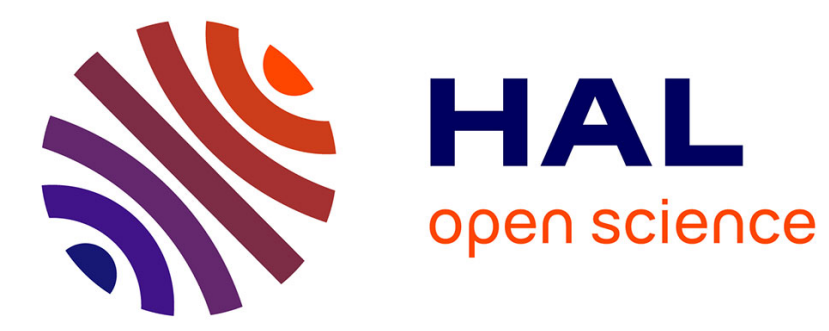

\title{
Catalytic Disproportionation of Formic Acid to Methanol using Recyclable Silylformates
}

Clément Chauvier, Arnaud Imberdis, Pierre Thuéry, Thibault Cantat

\section{To cite this version:}

Clément Chauvier, Arnaud Imberdis, Pierre Thuéry, Thibault Cantat. Catalytic Disproportionation of Formic Acid to Methanol using Recyclable Silylformates. Angewandte Chemie International Edition, 2020, 59 (33), pp.14019-14023. 10.1002/anie.202002062 . cea-02559737

\section{HAL Id: cea-02559737 https://hal-cea.archives-ouvertes.fr/cea-02559737}

Submitted on 30 Apr 2020

HAL is a multi-disciplinary open access archive for the deposit and dissemination of scientific research documents, whether they are published or not. The documents may come from teaching and research institutions in France or abroad, or from public or private research centers.
L'archive ouverte pluridisciplinaire HAL, est destinée au dépôt et à la diffusion de documents scientifiques de niveau recherche, publiés ou non, émanant des établissements d'enseignement et de recherche français ou étrangers, des laboratoires publics ou privés. 


\title{
Catalytic Disproportionation of Formic Acid to Methanol using Recyclable Silylformates
}

\author{
Clément Chauvier, ${ }^{\ddagger}$ Arnaud Imberdis, ${ }^{\ddagger}$ Pierre Thuéry and Thibault Cantat ${ }^{\star[a]}$
}

\begin{abstract}
A novel strategy to prepare methanol from formic acid without external reductant is presented. The overall process described herein consists in the disproportionation of silyl formates to methoxysilanes catalyzed by ruthenium complexes and the production of methanol thereof by simple hydrolysis. Aqueous solutions of $\mathrm{MeOH}(>1 \mathrm{~mL},>70 \%$ yield) were prepared in this manner. The sustainability of the reaction has been established by the recycling of the silicon-containing byproducts with cheap, readily available and environmentally-benign reagents.
\end{abstract}

The depletion of fossil fuels and their participation to the global warming increasingly calls for a paradigm shift in both the energy and chemical sectors to utilize renewable feedstocks as raw materials. Because of their highly oxidized nature, the upgrading of renewable carbon sources (incl. $\mathrm{CO}_{2}$ and biomass wastes) into value-added chemicals or fuels requires the development of efficient reduction methods to form energy-rich $\mathrm{C}-\mathrm{H}$ bonds preexisting in fossil hydrocarbons. This endeavour is a cornerstone in the reduction of $\mathrm{CO}_{2}$ to methanol, an important precursor to industrial chemicals, such as formaldehyde, acetic acid and light olefins, but also a promising molecule for energy storage applications. ${ }^{[1 \mathrm{a}-\mathrm{c}]}$ Notably, the so-called circular and carbonneutral methanol economy conceptualized by Olah relies on $\mathrm{CO}_{2}$ reduction to methanol via hydrogenation. ${ }^{[2]} \mathrm{A}$ variety of heterogeneous and homogeneous catalysts have been designed and optimized to circumvent the kinetic inertness of the apolar gases $\mathrm{H}_{2}$ and $\mathrm{CO}_{2}{ }^{[3 \mathrm{a}-\mathrm{f}]}$ Despite these efforts, the resulting processes involve energy intensive conditions, with the need for high operating pressures (> $50 \mathrm{bar}$ ), and/or pose selectivity problems, with $\mathrm{CO}$ and formate derivatives being obtained as side-products. Alternatively, $\mathrm{CO}_{2}$ can be reduced at the methoxy level under milder conditions by using polarized hydride donors, such as sacrificial hydrosilanes ${ }^{[4]}$ and hydroboranes ${ }^{[5]}$. Nevertheless, these methods are not sustainable as they produce stoichiometric amounts of non-reyclable silyl and boryl oxides as wastes. ${ }^{[6]}$

A conceptually different strategy has recently emerged to generate $\mathrm{CH}_{3} \mathrm{OH}$ from $\mathrm{CO}_{2}$ via the intermediacy of formic acid (FA). At the onset, $\mathrm{FA}$ is produced by a well-studied two-electron electroreduction of $\mathrm{CO}_{2}$ or, alternatively, through biomass reforming. The subsequent disproportionation of 3 equiv. FA produces $\mathrm{CH}_{3} \mathrm{OH}, \mathrm{CO}_{2}$ and water, so that the net cascade reaction is equivalent to the direct electroreduction or hydrogenation of $\mathrm{CO}_{2}$ to methanol (Scheme 1). This strategy,

[a] Dr. Clément Chauvier, Dr. Arnaud Imberdis, Dr. Pierre Thuéry and Dr. Thibault Cantat

$\mathrm{CC}$ and $\mathrm{Al}$ contributed equally to this work

Université Paris-Saclay, CEA, CNRS, NIMBE, 91191, Gif-surYvette, France

E-mail: thibault.cantat@cea.fr

Supporting information for this article is given via a link at the end of the document. which does not involve any additional reductant, requires efficient catalysts able to promote both the activation and disproportionation of FA. While the first catalyst, $\left[\mathrm{Cp} \operatorname{Ir}(\mathrm{bpy})\left(\mathrm{OH}_{2}\right)\right][\mathrm{OTf}]_{2}$ (bpy = 2,2'-bipyridine), reported by Goldberg, Miller et al., generated small quantities of $\mathrm{CH}_{3} \mathrm{OH}(<$ $3 \%),{ }^{[7]}$ our group obtained significantly improved yields of up to $50 \%$ from THF solutions of FA with a ruthenium(II) complex paired with the tripodal ligand triphos $\left(\mathrm{CH}_{3} \mathrm{C}\left(\mathrm{CH}_{2} \mathrm{PPh}_{2}\right)_{3}\right)^{\left[{ }^{[8]}\right.}$ Shortly thereafter, Parkin and Neary reported on the first base metal catalysts comprising molybdenum(II), which provided benzene solutions of $\mathrm{CH}_{3} \mathrm{OH}$ with yields up to $21 \%{ }^{[9]}$

Nonetheless, irrespective of the catalyst employed, $\mathrm{H}_{2}$ is always produced as a side product in at least $50 \%$ yield and this feature conveys a strong limitation of this disproportionative approach to methanol. Under standard conditions, the competitive dehydrogenation and the targeted disproportionation of FA indeed display similar overall energetics $\left(\Delta_{r} G_{D H}^{0}=\right.$ $-33 \mathrm{~kJ} \mathrm{~mol}^{-1}$ vs $\Delta_{r} G_{D P}^{0}=-36 \mathrm{~kJ} \cdot \mathrm{mol}^{-1}$ at $298 \mathrm{~K}$ for one mole $\mathrm{HCO}_{2} \mathrm{H}$ ), which have, thus far, not been bypassed by establishing a genuine kinetic control of the disproportionation. Laurenczy and Himeda recently showed that an iridium(III) complex catalyzes the low-temperature disproportionation of aqueous FA, with high selectivity $(96 \%),{ }^{[10]}$ only when the thermodynamic balance for the disproportionation was favored by applying a pressure of $\mathrm{H}_{2}$ (50 bar), in the presence of excess $\mathrm{H}_{2} \mathrm{SO}_{4}{ }^{\left[{ }^{[11]}\right.}$

Electroreduction or hydrogenation of $\mathrm{CO}_{2}$ :

$$
\mathrm{CO}_{2} \frac{+6 \mathrm{H}^{+}+6 \mathrm{e}^{-}}{\text {or }+3 \mathrm{H}_{2}} \rightarrow \mathrm{CH}_{3} \mathrm{OH}+\mathrm{H}_{2} \mathrm{O}
$$

Disproportionation and dehydrogenation of formic acid:

$$
\begin{gathered}
3 \mathrm{HCO}_{2} \mathrm{H}_{(\mathrm{l})} \underset{\Delta \mathrm{G}_{298 \mathrm{~K}}^{0}=-108 \mathrm{~kJ} / \mathrm{mol}}{\longrightarrow} \mathrm{CH}_{3} \mathrm{OH}_{(\mathrm{l})}+2 \mathrm{CO}_{2(\mathrm{~g})}+\mathrm{H}_{2} \mathrm{O}_{(\mathrm{l})} \\
\text { dehydrogenation } 3\left(\mathrm{CO}_{2(\mathrm{~g})}+\mathrm{H}_{2(\mathrm{~g})}\right) \\
\Delta \mathrm{G}_{298 \mathrm{~K}}^{0}=-99 \mathrm{~kJ} / \mathrm{mol}
\end{gathered}
$$

This work: disproportionation of silyl formates

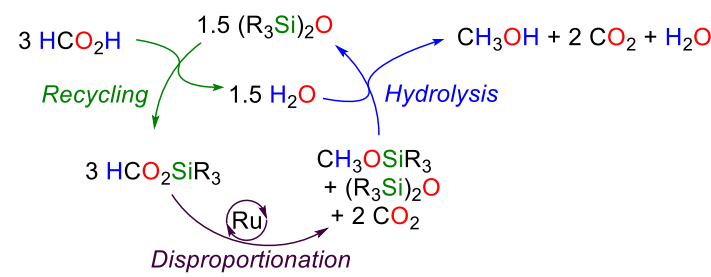

Scheme 1: Routes for the disproportionation of formic acid to methanol

To overcome this intrinsic thermodynamic limitation, we have sought an alternative disproportionative route to methanol, able to suppress the competing dehydrogenation pathway. Herein we wish to report a novel strategy based on the high-yielding catalytic disproportionation of silyl formates $\left(\mathrm{HCO}_{2} \mathrm{SiR}_{3}\right)$ to methoxysilanes $\left.\left(\mathrm{CH}_{3} \mathrm{OSiR}\right)_{3}\right)$ and $\mathrm{CO}_{2}$ followed by the release of free $\mathrm{CH}_{3} \mathrm{OH}$ by hydrolysis. In a distinct step, the silylformate is reformed by recycling the silicon-containing byproducts generated throughout the process with formic acid (Scheme 1). 
Silyl formates $\left(\mathrm{HCO}_{2} \mathrm{SiR}_{3}\right)$ feature a formate ligand coordinated to a silicon atom and these species can mimic the behaviour of a genuine hydrosilane $\left(\mathrm{HSiR}_{3}\right)$, in the presence of an oxidant and a suitable catalyst. ${ }^{[12 a-b]}$ As a proof-of-concept, our group has recently reported the reduction of aldehydes by transfer hydrosilylation using the ruthenium(II) complex $\left[\mathrm{Ru}\left(\eta^{1}-\mathrm{OAc}\right)\left(\kappa^{2}-\right.\right.$ OAc) $\left(\kappa^{3}\right.$-triphos)] (1) as a catalyst. ${ }^{[13]}$ In 2018, Hong and coworkers showed that silyl formates can also act as oxidants as their catalytic reduction with $\mathrm{H}_{2}$ afforded methanol and silanols in the presence of ruthenium pincer complexes. ${ }^{[14]}$ The combination of our and Hong's results suggest that silyl formates possess an amphoteric redox behavior, able to serve both as reductants and as oxidants. The disproportionation of silyl formates to generate methoxysilanes was therefore investigated, for the first time.

At the outset, the transfer hydrosilylation catalyst 1 was envisaged, but failed to promote the disproportionation of triethylsilyl formate $\left(\mathrm{Et}_{3} \mathrm{SiOCHO}, 2 \mathrm{a}\right)$ into the corresponding methoxysilane $3 a$ under various reaction conditions (e.g. entry 1 in Table 1). In several occasions, we were able to clarify the fate of complex 1 in the reaction medium and could identify by X-Ray diffraction the known [(triphos) $\left.\mathrm{RuH}_{2}(\mathrm{CO})\right],{ }^{[15]}$ which is presumably formed by decarbonylation of $\mathbf{2 a}$ and is catalytically inactive. ${ }^{[16]}$ Formate esters or aldehydes are indeed known to yield carbonyl complexes, which in the case of tripodal ligands such as triphos are often inactive in reduction chemistry because of the lack of a vacant coordination site and the reduced hydricity of $\mathrm{Ru}-\mathrm{H}$ intermediates. To circumvent this limitation, Kuriyama et al. introduced the so-called Ru-MACHO complex $\left[\mathrm{RuHCl}(\mathrm{CO})\left(\mathrm{PN}^{\mathrm{H}} \mathrm{P}^{\mathrm{Ph}}\right)\right]$ (4) ligated by the aliphatic pincer aminodiphosphine $\mathrm{HN}\left(\mathrm{CH}_{2} \mathrm{CH}_{2} \mathrm{PPh}_{2}\right)_{2} \quad\left(\mathrm{PN}^{\mathrm{H}} \mathrm{P}^{\mathrm{Ph}}\right)$ for the hydrogenation of esters and we thus evaluated this class of ligand for the disproportionation of $\mathbf{2 a} .^{[17]}$

Table 1. Optimization of the disproportionation of silyl formate $\mathbf{2 a}$

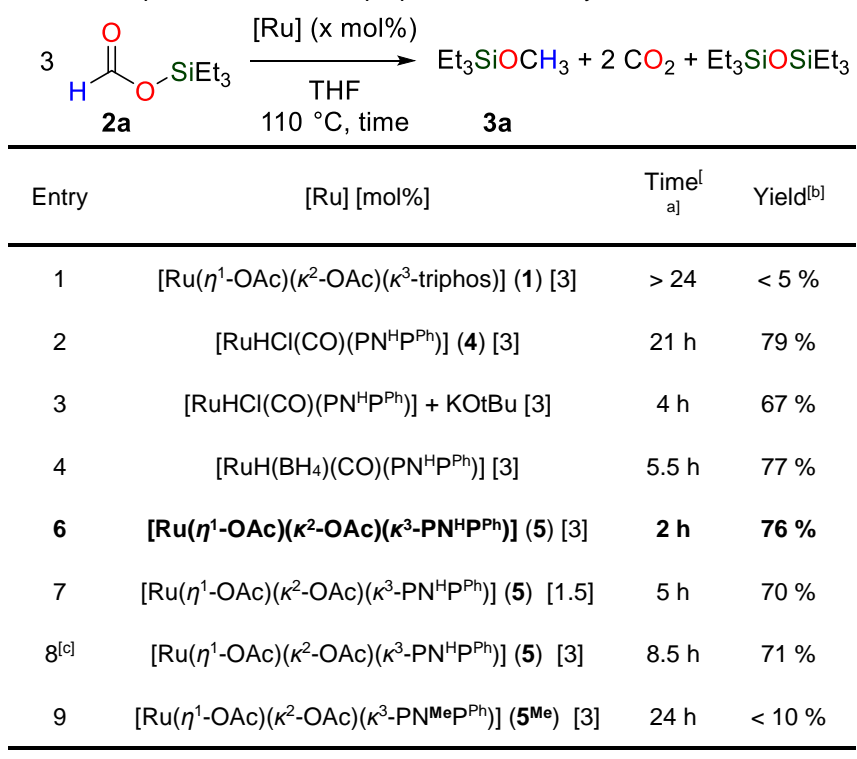

Reaction conditions: $2 a(0.14 \mathrm{mmol})$, cat. $(\mathrm{x} \mathrm{mol} \%), 110^{\circ} \mathrm{C}, \mathrm{THF}-\mathrm{d}_{8}(0,4$ $\mathrm{mL})$. [a] time to reach full conversion. [b] Yields were determined by ${ }^{1} \mathrm{H}$ NMR analysis of the crude mixture using mesitylene as an internal standard. [c] Reaction carried out at $90^{\circ} \mathrm{C}$.
Gratifyingly, using $3 \mathrm{~mol} \%$ of catalyst $\mathbf{4}$, the silyl formate $\mathbf{2 a}$ decomposed into methoxysilane $\mathbf{3 a} \quad\left(\delta_{\mathrm{H}}=3.42 \mathrm{ppm}\right.$ and $\left.\delta_{\mathrm{C}}=50.8 \mathrm{ppm}\right)$ in $79 \%$ yield $(90 \%$ conversion) after $21 \mathrm{~h}$ at $110^{\circ} \mathrm{C}$ in THF (entry 2, Table 1). $\mathrm{CO}_{2}$ was also detected in solution by ${ }^{13} \mathrm{C}$ NMR spectroscopy $\left(\delta_{\mathrm{C}}=126.0 \mathrm{ppm}\right)$, thereby establishing the disproportionative nature of this new transformation of silyl formates. Although the addition of catalytic amounts of $\mathrm{KO} B \mathrm{Bu}$ to complex 4 afforded methoxysilane in a decreased $67 \%$ yield, it also improved the kinetics of the reaction (entry 3), suggesting that replacing the chloride ligands in $\mathbf{4}$ with oxygen donors might be beneficial. The reactivity of other ruthenium complexes was thus explored (see SI for full details of the optimization studies) and we found that the catalysis with borohydride complex $\left[\mathrm{RuH}\left(\mathrm{BH}_{4}\right)(\mathrm{CO})\left(\mathrm{PN}^{\mathrm{H}} \mathrm{P}^{\mathrm{Ph}}\right)\right]$ provided $3 \mathrm{a}$ in $77 \%$ yield after a lower reaction time of $5.5 \mathrm{~h}$ at $110^{\circ} \mathrm{C}$. This borohydride ruthenium complex also displays catalytic activity for the hydrogenation of $\mathbf{2 a}$ as demonstrated by Hong and coworkers. ${ }^{[14]}$

Finally, the kinetics of disproportionation could be improved with the novel ruthenium complex $\left[\mathrm{Ru}\left(\eta^{1}-\mathrm{OAc}\right)\left(\kappa^{2}-\mathrm{OAc}\right)\left(\kappa^{3}-\right.\right.$ $\left.\left.\mathrm{PN}^{\mathrm{H} P \mathrm{Ph}}\right)\right](5)$ without any additive. 5 be easily synthesized in $81 \%$ isolated yield as a single isomer from free $\mathrm{PN}^{\mathrm{H}} \mathrm{P}^{\mathrm{Ph}}$ ligand and $\left[\mathrm{Ru}\left(\eta^{1}-\mathrm{OAc}\right)\left(\kappa^{2}-\mathrm{OAc}\right)\left(\eta^{6}\right.\right.$-cymene $\left.)\right]$ in THF (Scheme 2). 5 was fully characterized by ${ }^{1} \mathrm{H},{ }^{13} \mathrm{C}$ and ${ }^{31} \mathrm{P}$ NMR spectroscopy and its structure unambiguously assigned by $\mathrm{X}$-ray diffraction analysis. It comprises the $\mathrm{PN}^{\mathrm{H}} \mathrm{P}^{\mathrm{Ph}}$ ligand facially coordinated to the $\mathrm{Ru}$ " ion with the two acetate ligands being inequivalent at the NMR time scale (see $\mathrm{SI})$.
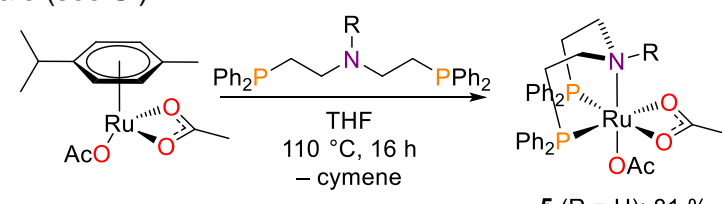

$5(\mathrm{R}=\mathrm{H}): 81 \%$

$5^{\mathrm{Me}}\left(\mathrm{R}=\mathrm{CH}_{3}\right): 65 \%$

Scheme 2: Preparation of complexes $5(R=H)$ and its $\mathrm{N}$-methylated analogue $5^{\mathrm{Me}}\left(\mathrm{R}=\mathrm{CH}_{3}\right)$.

Complex $\mathbf{5}$ enables the formation of methoxysilane $\mathbf{3 a}$ from 2a in $76 \%$ and $70 \%$ yield after $2 \mathrm{~h}$ and $5 \mathrm{~h}$ at $110{ }^{\circ} \mathrm{C}$, with a catalyst loading of 3 and $1.5 \mathrm{~mol} \%$, respectively (entries 6 and 7 ). 5 is also active at milder temperature $\left(90^{\circ} \mathrm{C}\right)$, albeit at the expense of an increased reaction time $(71 \%$ yield $3 \mathrm{a}$ after $8.5 \mathrm{~h}$; entry 8) as well as in non-polar solvents such as benzene or cyclohexane (see SI). Importantly, the $\mathrm{NH}$ functionality on the ligand backbone proved to be fundamental for the catalytic disproportionation of $\mathbf{2 a}$, as replacing catalyst $\mathbf{5}$ with its $\mathbf{N}$ methylated analogue $\left(5^{\mathrm{Me}}, \mathrm{R}=\mathrm{CH}_{3}\right.$ on Scheme 2$)$ led to only $10 \%$ yield of $3 a$ after $24 \mathrm{~h}$ at $110{ }^{\circ} \mathrm{C}$.

Beyond triethylsilylformate $\mathbf{2 a}$, the formates $\mathbf{2 b} \mathbf{b} \mathbf{d}$ featuring silyl groups with diverse steric and electronic properties were also readily decomposed into methanol derivatives $\mathbf{3 b} \mathbf{b}-\mathbf{d}$, in the presence of complex $5(3 \mathrm{~mol} \%)$ at $110^{\circ} \mathrm{C}$ in THF (as well as in cyclohexane and nonane for the silyl formate $\mathbf{2 b}$ ) (Scheme 3 ). In these cases, the methoxysilanes are accompanied with small amounts $(<8 \%)$ of the corresponding silylacetals intermediates $\left(\mathrm{R}_{3} \mathrm{SiOCH}_{2} \mathrm{OR}_{3} \mathrm{Si}\right)$ resulting from the exchange of formate and acetate anion at silicon. 


$$
\begin{aligned}
& \underset{\mathbf{2 b}-\mathbf{f}}{\stackrel{\mathrm{H}}{\mathrm{O}}-\mathrm{SiR}_{3}} \frac{\mathbf{5}(3 \mathrm{~mol} \%)}{110^{\circ} \mathrm{C}, \mathrm{THF}} \underset{\mathbf{3 b}-\mathbf{f}}{\mathrm{H}_{3} \mathrm{C}^{-}-\mathrm{SiR}_{3}}+2 \mathrm{CO}_{2}+\mathrm{R}_{3} \mathrm{SiOSiR}_{3} \\
& \mathrm{H}_{3} \mathrm{C}^{-} \mathrm{O}_{-} \mathrm{SiMe}_{3} \quad \mathrm{H}_{3} \mathrm{C}^{-} \mathrm{O}_{-} \mathrm{SiPhMe}_{2} \quad \mathrm{H}_{3} \mathrm{C}^{-} \mathrm{O}_{-} \mathrm{SiPh}_{2} \mathrm{Me} \\
& 93 \%(1 h)^{[a]} \\
& 87 \%(21 \mathrm{~h})^{[\mathrm{b}]} \\
& \mathrm{H}_{3} \mathrm{C}^{-} \mathrm{O}_{-} \mathrm{SiPr}_{3} \quad \mathrm{H}_{3} \mathrm{C}^{-} \mathrm{O}_{-} \mathrm{SiBuMe}_{2} \\
& \text { 3e: }<5 \% \quad 3 \mathbf{3 f}:<5 \%(>24 \mathrm{~h})
\end{aligned}
$$

Scheme 3. Scope of the disproportionation of silyl formates. Reaction conditions: $2(0.14 \mathrm{mmol}), 5(3 \mathrm{~mol} \%), 110{ }^{\circ} \mathrm{C}$, THF- $d_{8}(0,4 \mathrm{~mL})$. Time to reach full conversion in brackets. Yields were determined by ${ }^{1} \mathrm{H}$ NMR analysis of the crude mixture using mesitylene as an internal standard. [a] Reaction carried out in cyclohexane- $d_{12}$. [b] Reaction carried out in nonane.

Silyl formates comprising bulky silyl groups such as TIPS (2e) or TBDMS (2f) did not yield the corresponding methoxysilanes. With $2 \mathbf{2}$, the conversion remained very low (<10\%) after more than $24 \mathrm{~h}$ at $110^{\circ} \mathrm{C}$ in THF or benzene and $3 f$ was barely present (< $5 \%$ ). However, formate $2 \mathrm{e}$ behaved differently: its full conversion was observed within $6.5 \mathrm{~h}$ at $110^{\circ} \mathrm{C}$ in THF and the corresponding silanol $\left(\mathrm{Pr}_{3} \mathrm{SiOH}\right)$ was the major product $(80 \%$ yield) detected in solution by NMR spectroscopy along with small amounts of $3 \mathrm{e}$ and methyl formate. Analysis of the gaseous headspace by GC revealed the presence of carbon monoxide, thereby pointing to a competitive decarbonylation of $2 \mathbf{f}$ catalyzed by $5\left(\mathrm{Pr}_{3} \mathrm{SiOCHO} \rightarrow i \mathrm{Pr}_{3} \mathrm{SiOH}+\mathrm{CO}\right)$.

In fact, minor decarbonylation pathways are also available with less hindered silyl formates such as $2 \mathbf{a}$. Monitoring the decomposition of ${ }^{13} \mathrm{C}$-labelled $2 \mathrm{a}$ by ${ }^{13} \mathrm{C}$ NMR spectroscopy with $3 \mathrm{~mol} \% \mathbf{5}$ indeed reveals the presence of small amounts of free ${ }^{13} \mathrm{CO}\left(\delta_{\mathrm{C}}=185.3 \mathrm{ppm}\right.$ in THF $)$, from the early stages of the reaction, along with the major products: ${ }^{13} \mathrm{CO}_{2}$ and ${ }^{13} \mathrm{CH}_{3} \mathrm{OSiEt}_{3}$ (3a). In addition, two novel hydride ruthenium complexes, $\mathbf{6}$ and $\mathbf{7}$ (Scheme 4), containing respectively one and two ${ }^{13} \mathrm{CO}$ ligands were also identified in the catalytic medium at room temperature (6: $\delta_{\mathrm{CO}}=206.5 \mathrm{ppm} ; 7: \delta_{\mathrm{CO} 1}=201.6 \mathrm{ppm} \& \delta_{\mathrm{CO} 2}=193.3 \mathrm{ppm}$, ${ }^{2} J_{\mathrm{C}-\mathrm{C}}=3.5 \mathrm{~Hz}$ ). Complex 6 could be independently synthesized in $65 \%$ isolated yield from 5 and an excess of 2a (4 equiv.) at $110^{\circ} \mathrm{C}$ in toluene, while cationic 7 could be prepared in $54 \%$ isolated yield by exposing a toluene solution of 6 to an atmosphere of $\mathrm{CO}$ (1 bar) and both were characterized by NMR spectroscopy and X-Ray diffraction (see SI). Importantly, complexes $\mathbf{6}$ and $\mathbf{7}$ are competent catalysts in the disproportionation of silyl formate $\mathbf{2 a}$ into $\mathbf{3 a}$ and $\mathrm{CO}_{2}$ in $70 \%$ and $60 \%$ yield after $4 \mathrm{~h}$ and $5 \mathrm{~h}$, respectively. This not only suggests that $\mathbf{6}$ and $\mathbf{7}$ are resting states of the catalytic system, but also clearly demonstrates that decarbonylation at ruthenium does not shut down the catalytic activity. Furthermore, the catalytic system tolerates well free $\mathrm{CO}$ as disproportionation catalyzed by $\mathbf{5}$ still occurs under $1 \mathrm{~atm}$ of $\mathrm{CO}$ (66\% yield) in the presence of triethylsilanol $\left(\mathrm{Et}_{3} \mathrm{SiOH}\right)$.

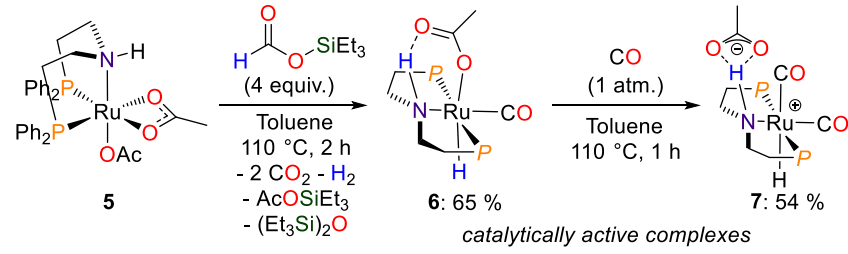

Scheme 4: Independent synthesis of complexes 6 and 7 from 5. ${ }^{[18]}$

To further demonstrate the utility of the disproportionation of silyl formates in the overall conversion of FA to methanol, the catalytic disproportionation of $\mathbf{2 b}$ was performed on a preparative scale $(15.6 \mathrm{mmol}, 2 \mathrm{~mL})$ with a low loading of pre-catalyst 5 ( $0.75 \mathrm{~mol} \%)$. Nonane was selected as solvent because its high boiling point $\left(151^{\circ} \mathrm{C}\right)$ facilitates the isolation of the somewhat volatile trimethylsilylated products (b.p. $57^{\circ} \mathrm{C}$ and $101^{\circ} \mathrm{C}$ for $3 \mathbf{b}$ and hexamethyldisiloxane (HMDSO), respectively). Under these conditions, the desired methoxysilane $\mathbf{3 b}$ and the siloxane $\left(\mathrm{Me}_{3} \mathrm{Si}_{2} \mathrm{O}\right.$ were produced in $85 \%$ yield after ca. $50 \mathrm{~h}$ at $110^{\circ} \mathrm{C}$ (Scheme 5). Their separation from the reaction medium was conveniently carried out by distillation (at $130^{\circ} \mathrm{C}$ ), leaving a suspension of the catalyst in nonane. The addition of an excess of water (ca. 10 equiv with respect to $3 \mathbf{b})^{[19]}$ to the resulting mixture of $\mathbf{3 b}$ and $\left(\mathrm{Me}_{3} \mathrm{Si}\right)_{2} \mathrm{O}$ afforded, after $20 \mathrm{~h}$ at $80^{\circ} \mathrm{C}$, a biphasic solution comprising an aqueous methanol layer $(3.4 \mathrm{M}$, $3.69 \mathrm{mmol} ; 71 \%$ yield from $\mathbf{2 b}$ ) covered with a layer of the hydrophobic HMDSO (73\% yield from $\mathbf{2 b}$, NMR purity >95\%).

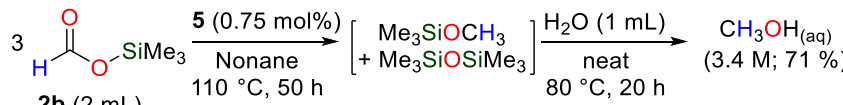

$$
\begin{aligned}
& \text { 2b }(2 \mathrm{~mL}) \quad-2 \mathrm{CO}_{2} \quad-3 / 2 \mathrm{Me}_{3} \mathrm{SiOSiMe}_{3} \\
& (1.2 \mathrm{~mL} ; 73 \%)
\end{aligned}
$$

Scheme 5: Upscaled methanol production by disproportionation of silyl formate $\mathbf{2 b}$ followed by hydrolysis of methoxytrimethylsilane.

The sequential catalytic disproportionation of $\mathbf{2} \mathbf{b}$ followed by the hydrolysis of $\mathbf{3 b}$ leaves HMDSO as the sole silylated bya)

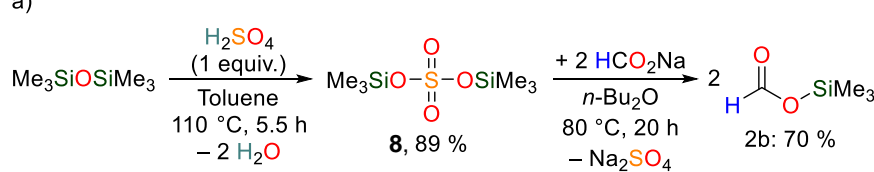
b)

$$
\text { The net reaction balance: } 3 \mathrm{NaOCHO}_{1.5 \mathrm{SO}_{4}\left(\mathrm{SiMe}_{3}\right)_{2}}
$$

The net reaction balance:

Scheme 6: a) Recycling of HMDSO into silyl formate $\mathbf{2 b}$, b) balance sheet of the overall process, the yields in parentheses are non-isolated. [a] overall isolated yield of the disproportionation event followed by hydrolysis. 
product of the process. Although disiloxanes are generally considered as terminal wastes in hydrosilylation reactions, we envisioned the possible recycling HMDSO into $\mathbf{2} \mathbf{b}$, as both compounds feature a strong $\mathrm{Si}-\mathrm{O}$ bond. Although HMDSO has been used for the silylation of carboxylic acids, in the presence of $\mathrm{H}_{2} \mathrm{SO}_{4}$ as a catalyst, ${ }^{[20]}$ this procedure could not be transposed to convert $\mathrm{FA}$ to $\mathbf{2 b}$ presumably because (i) sulphuric acid readily decarbonylates $\mathrm{FA}^{[21]}$ and (ii) $\mathrm{FA}$ and water form an azeotrope mixture, that prevents shifting the equilibrium towards the consumption of FA by water distillation. This difficulty was overcome through a first activation of HMDSO with sulfuric acid (Scheme $6 \mathrm{a}$ ), which affords after $5.5 \mathrm{~h}$ at reflux of toluene the solid bis(trimethylsilyl)sulfate 8 in $89 \%$ isolated yield. The formulation of 8 as $\mathrm{SO}_{4}\left(\mathrm{SiMe}_{3}\right)_{2}$ was confirmed by X-Ray diffraction (see $\mathrm{SI}$ ), formation of which was postulated by Dunogues et al. nearly 55 years ago. ${ }^{[22]}$ Interestingly, 8 features highly electrophilic silicon atoms that readily react with a variety of nucleophiles. ${ }^{[23]}$ Accordingly, 8 reacted with sodium formate to give silyl formate $\mathbf{2 b}$ in $70 \%$ isolated yield (92\% purity), after separation from the solid by-product $\mathrm{Na}_{2} \mathrm{SO}_{4}$ and the dibutyl ether solvent by distillation.

The two-step protocol depicted in Scheme 6a affords an efficient recycling procedure for the conversion of the siloxane byproduct to the starting trimethylsilyl formate $\mathbf{2} \mathbf{b}$. The net reaction balance involves the utilization of sodium formate and sulphuric acid to obtain methanol and sodium sulfate in $77 \%$ yield in nonane ( $44 \%$ isolated yield), while $77 \%$ of the silicon compounds can be recycled ( $45 \%$ isolated yield) (Scheme $6 \mathrm{~b}$ ). This methanol yield outperforms most of the state-of-the-art FA disproportionation protocols and compares well to the recent report of Himeda, Laurenczy et al., who obtained $75 \% \mathrm{MeOH}$ yield in $\mathrm{D}_{2} \mathrm{O}$, using stoichiometric quantities of $\mathrm{H}_{2} \mathrm{SO}_{4}{ }^{[10]}$ The overall process also affords $\mathrm{CO}_{2}$ as a byproduct (2 equiv. relative to methanol), which is inevitably produced during the disproportionation step and can be recycled to formates by a 2 electron reduction.

These results hence show how shutting down the dehydrogenation of formic acid by replacing a proton with a silyl group can provide a high yielding, globally redox-neutral and operationally simple disproportionation route to methanol. While hydrosilylation chemistry with genuine hydrosilanes is hampered by the generation of siloxane wastes, ${ }^{[6]}$ this work also demonstrates for the first time that reductive chemistry with silicon-based reductants can be amenable to renewability via the recycling of silyl formates from spent siloxanes.

Keywords: disproportionation $\bullet$ formic acid $\bullet$ silyl formate $•$ methanol $\cdot$ ruthenium

[1] a) A. Goeppert, M. Czaun, J.-P. Jones, G. K. Surya Prakash, G. A. Olah, Chem. Soc. Rev. 2014, 43, 7995-8048. b) E. V. Anderson, Chem. Eng News 1993, 71, 9-15. c) A. Demirbas, Energy Convers. Manag. 2008 49, 125-130.

[2] G. A. Olah, Angew. Chemie Int. Ed. 2005, 44, 2636-2639.

[3] a) X. Dong, F. Li, N. Zhao, F. Xiao, J. Wang, Y. Tan, Appl. Catal. B Environ. 2016, 191, 8-17. b) J. Xiao, D. Mao, X. Guo, J. Yu, Appl. Surf Sci. 2015, 338, 146-153. c) J. Siwawut, P. Namkhang, P. Kongkachuichay, Chem. Eng. Technol. 2015, 38, 2153-2160. d) K.
Tominaga, Y. Sasaki, M. Kawai, T. Watanabe, M. Saito, J. Chem. Soc Chem. Commun. 1993, 629. e) S. Wesselbaum, V. Moha, M. Meuresch, S. Brosinski, K. M. Thenert, J. Kothe, T. vom Stein, U. Englert, M. Hölscher, J. Klankermayer, et al., Chem. Sci. 2015, 6, 693-704. f) J. Toyir, P. R. de la Piscina, J. L. G. Fierro, N. Homs, Appl. Catal. B Environ. 2001, 29, 207-215.

[4] F. J. Fernández-Alvarez, L. A. Oro, ChemCatChem 2018, 10, 4783-4796.

[5] S. Bontemps, Coord. Chem. Rev. 2016, 308, 117-130.

[6] C. Chauvier, T. Cantat, ACS Catal. 2017, 7, 2107-2115.

[7] A. J. M. Miller, D. M. Heinekey, J. M. Mayer, K. I. Goldberg, Angew. Chemie Int. Ed. 2013, 52, 3981-3984.

[8] S. Savourey, G. Lefèvre, J.-C. Berthet, P. Thuéry, C. Genre, T. Cantat, Angew. Chem. Int. Ed. 2014, 53, 10466-10470.

[9] M. C. Neary, G. Parkin, Chem. Sci. 2015, 6, 1859-1865.

[10] K. Sordakis, A. Tsurusaki, M. Iguchi, H. Kawanami, Y. Himeda, G. Laurenczy, Green Chem. 2017, 19, 2371-2378.

[11] $\mathrm{H}_{2} \mathrm{SO}_{4}$ improves the kinetics of the reaction by protonation of $\mathrm{FA}$ and drives the equilibrium to the right via. its dissecant properties.

[12] a) T. Godou, C. Chauvier, P. Thuéry, T. Cantat, Synlett 2017, 28, 2473 2477. b) C. Chauvier, T. Godou, T. Cantat, Chem. Commun. 2017, 53, 11697-11700

[13] C. Chauvier, P. Thuéry, T. Cantat, Angew. Chem. Int. Ed. 2016, 55, 14096-14100.

[14] J. Koo, S. H. Kim, S. H. Hong, Chem. Commun. 2018, 54, 4995-4998.

[15] V. I. Bakhmutov, E. V Bakhmutova, N. V Belkova, C. Bianchini, L. M. Epstein, D. Masi, M. Peruzzini, E. S. Shubina, E. V Vorontsov, F. Zanobini, Can. J. Chem. 2001, 79, 479-489.

[16] T. vom Stein, M. Meuresch, D. Limper, M. Schmitz, M. Hölscher, J. Coetzee, D. J. Cole-Hamilton, J. Klankermayer, W. Leitner, J. Am. Chem. Soc. 2014, 136, 13217-13225.

[17] W. Kuriyama, T. Matsumoto, O. Ogata, Y. Ino, K. Aoki, S. Tanaka, K. Ishida, T. Kobayashi, N. Sayo, T. Saito, Org. Process Res. Dev. 2012 16, 166-171.

[18] For ruthenium-based complexes analogous to 6 isolated in the context of hydrogenative or dehydrogenative studies, see a) J. Kothandaraman M. Czaun, A. Goeppert, R. Haiges, J.-P. Jones, R. B. May, G. K. S. Prakash, G. A. Olah, ChemSusChem 2015, 8, 1442-1451. b) D. H. Nguyen, X. Trivelli, F. Capet, Y. Swesi, A. Favre-Réguillon, L. Vanoye, F. Dumeignil, R. M. Gauvin, ACS Catal. 2018, 8, 4719-4734. c) E. Alberico, A. J. J. Lennox, L. K. Vogt, H. Jiao, W. Baumann, H.-J. Drexler, M. Nielsen, A. Spannenberg, M. P. Checinski, H. Junge, et al., J. Am Chem. Soc. 2016, 138, 14890-14904.

[19] S. W. Kantor, J. Am. Chem. Soc. 1953, 75, 2712-2714.

[20] H. Matsumoto, Y. Hoshino, J. Nakabayashi, T. Nakano, Y. Nagai, Chem. Lett. 1980, 9, 1475-1478.

[21] R. E. DeRight, J. Am. Chem. Soc. 1933, 55, 4761-4764.

[22] N. Duffaut, R. Calas, J. Dunoguès, Bull. Soc. Chim. Fr. 1963, 1, 512.

[23] S. N. Borisov, M. G. Voronkov, E. Y. Lukevits, in Organosilicon Deriv. Phosphorus Sulfur, Springer US, Boston, MA, 1971, pp. 157-333. 